Japanese Pryhological Researth

1995 , Vol 37, No. $4,221-228$

\title{
Visual evoked potentials to geometric forms ${ }^{1}$
}

\author{
MOTOO ITO: and TATSUYA SUGATA \\ Department of Psychology, Faculty of Letters, Aichi Gakuin University, Nisshin. Aichi 470-01
}

\begin{abstract}
We recorded transient visual evoked potentials (VEPs) to three kinds of geometric figures (equilateral triangle. square, and circle). These three figures were of equal area, equal contour length, or equal ratio of contour length to area. They were presented monocularly below the fixation point (FP). Angular separation between FP and the figure was held constant. Transient visual evoked potentials (VEPs) were recorded monopolarly from seven electrodes around the occipital area of eight subjects. The grand average of the subtracted waves was obtained between the figure and blank (control) conditions. N1 (mean peak latency: $160 \mathrm{~ms})$ and $\mathrm{P} 2(240 \mathrm{~ms})$ waves were identified. ANOVAs were conducted for latency and amplitude. For the N1 amplitude, the triangle evoked a significantly larger response than did the other two figures in all stimulus conditions. No significant difference was found between the square and the circle. A similar effect was obtained for the P2 amplitude, but it was not as remarkable as for the NI amplitude. There was no significant effect of form on the $\mathrm{N1}$ and $\mathrm{P} 2$ latencies.
\end{abstract}

Key words: form perception, geometric figures, transient visual evoked potentials

When flash and patterned figures are presented in the visual field at lower or higher temporal frequencies, transient or steadystate visual evoked potentials (VEPs) are obtained from the occipital area of the human scalp (Kinney, 1977; Regan, 1977). Findings on the relationship between stimulus variables and VEPs have been accumulated and have provided basic knowledge of the visual information processing (Barber, 1980; Desmedt, 1977, 1990; Morotomi, 1992; Nodar \& Barber, 1984; Papakostopoulos,

\footnotetext{
' Part of the data in the present article was reported at the 53rd Annual Convention of the Japanese Psychological Association (1989).

${ }^{2}$ The authors are deeply indebted to Prof. K. Tsuji of Nagoya University for his critical reading and comments on this manuscript and Mr. H. Kuwabara of Aichi Gakuin University for his cooperation in running experiments and analyzing data. Thanks are also expressed to Prof. R. Osaka of Aichi Gakuin University, Dr. D. A. Jeffreys of Keele University, Prof. G. F. A. Harding of Aston University and Dr. J. S.Kerr of Surrey University for their advice and encouragement.

${ }^{3}$ Now at Department of Social Welfare, Holy Cross College, Komono, Mie 510-12.
}

Butler, \& Martin, 1985, Regan, 1989). We also have been concerned with effects of brightness and contrast upon transient VEPs (Ito, 1986, 1987; Ito, Sugishita, Ito, Miyake, \& Tsuji, 1981). The present study was centered on the effect of form.

A problem accompanying the experiments in this field is what type of stimulus should be used. Many studies have presented checkerboard and grating to obtain pattern VEPs (Ermolaev, 1985; Kriss \& Barrett, 1985; MacKay \& Jeffreys, 1973; Regan \& Spekreijse, 1986; Spehlmann, 1965). In the present experiments, three geometric figures (an equilateral triangle, a square, and a circle) were presented on two grounds. Firstly, our visual world consists of vertical, horizontal, oblique and curved lines, and the three figures are supposedly fundamental, as Dondis (1973) described. Secondly, many psychophysical studies have shown that, among these three, the triangle is the most visible when stimulus size is equalized (Torii, 1969 Yokose, 1968; Zusne, 1970). It is therefore expected that VEPs have a correspondence to these forms.

Some studies have been concerned with 
the effect of geometric forms. John, Herrington, and Sutton (1967), using a square, a diamond and a circle, obtained different VEPs for different forms of equal area and similar VEPs for the same forms of different area. Kakigi, Miyazaki, and Mori (1972) examined the VEPs caused by a triangle, a square and a circle of equal area and found that the amplitude for the square was larger than that for the triangle. They attributed the result to the difference in retinal size, not to the difference in form. Jeffreys (1989) reported that, in comparison with a pattern of squares (or circles), a corresponding pattern of irregular elements evoked a larger late positive wave. Moskowitz, Armington, and Timberlake (1974), on the other hand, examined the effect of cornered and rounded herringbone patterns upon VEPs. The largest VEPs were for $90^{\circ}$-corner pattern and the VEPs for $45^{\circ}$-corner pattern were larger than those for $135^{\circ}$-corner pattern. Cornered and rounded patterns evoked greater responses than did the $180^{\circ}$-straight pattern. These findings led them to point out a crucial effect of angles upon pattern VEPs. Rietveld, Tordoir, Hagenouw, Lubbers, and Spoor (1967) also reported that the presence of a right or an acute angle between contrast borders in a pattern was essential in eliciting the larger VEP amplitude.

Since the results of previous studies are thus inconsistent and fragmentary, data must be accumulated systematically in a similar situation to make the findings conclusive. In the present study we examined the effect of form upon the VEPs using the above-mentioned geometric figures of equal area, equal contour length, and equal ratio of contour length to area.

\section{Experiment I}

Although the previous studies, except for Jeffreys (1989), have used flashed patterns, we presented outline figures to minimize the effect of luminance change. The larger VEPs have been obtained by a stimulus given at the lower part of the visual field and visuotopic or retinotopic projection to the visual cortex has been considered as an important condition to elicit a simple waveform (Jeffreys, 1977; Morotomi, 1986). Therefore, figures were presented below the fixation point.

\section{Method}

Subjects. Eight psychology students (21-45 years of age) participated. Six were males, two were females. They all had normal visual acuity by wearing optical correction where necessary.

Stimulus presentation. A 3-channel tachistoscope (Gerbrands T-3B-2) was used. The channels were assigned to stimulus field (SF), adaptation field (AF) and fixation point (FP), respectively. SF and AF had rectangular apertures of the same size (visual angle: $6^{\circ} 22^{\prime} \times 9^{\circ} 6^{\prime}$ ). Each of three outline figures (an equilateral triangle, a square and a circle) was successively presented in the center of the aperture of SF (duration: $50 \mathrm{~ms}$ ). The figures were drawn on white papers with black ink (line width: $1 \mathrm{~mm}$ ). The figures were of equal area $\left(9 \mathrm{~cm}^{2}\right)$, equal length $(12 \mathrm{~cm})$, and equal length/area (1.33), as Figure 1 shows. The subject was exposed to the blank AF against which SF was successively presented (ISI: $2-3 \mathrm{~s}$ ). Luminance of both fields was 5 $\mathrm{cd} / \mathrm{m}^{2}$.

The time required to switch from one field to another was $0.1 \mathrm{~ms}$. A small red spot of LED was constantly presented as FP. Through a small aperture for the right eye, the subject monocularly observed the figure presented below FP at a distance of $80 \mathrm{~cm}$. The left eye was kept open during the experiment. The angular separation between FP and the center of the figure was held constant at $3^{\circ}$ (Figure 1 (a)). The control was the condition in which a blank visual field (no figure) 
was presented in SF. Four sessions were conducted. Each consisted of 40 presentations of the figure and the control conditions in random order.

$V E P$ recording. VEPs were obtained by referential recording. Seven $\mathrm{Ag}-\mathrm{AgCl}$ electrodes were placed at two orthogonal rows, one longitudinal (midline) and the other transverse, i.e. at inion. 4.7 and $10 \mathrm{~cm}$ above it (I, I4, 17, I10), Cz. and at $5 \mathrm{~cm}$ to the left and right from $\mathrm{I}+$ (L5, R5). The left earlobe was used as reference and the right earlobe as ground. EEG $(0.5-30 \mathrm{~Hz})$ was amplified with an 8-channel polygraph (NEC San-ei System 360) and monitored with an oscilloscope. The amplified signals were recorded together with the signals triggered by the stimulus onset using a 14-channel data recorder (TEAC XR-510). Noiseless data were processed off-line with a signal processor (NEC San-ei 7T17). Analysis time for averaging was $512 \mathrm{~ms}$ of $100 \mathrm{~ms}$ prestimulus period and $412 \mathrm{~ms}$ stimulus period (sampling interval: $1 \mathrm{~ms}$ ). VEPs were summed for 40 presentations per trial. Secondary summation and subtraction were made when necessary.

\section{EQUAL AREA EQUAL LENGTH EQUAL LENGTH/AREA}

(a)
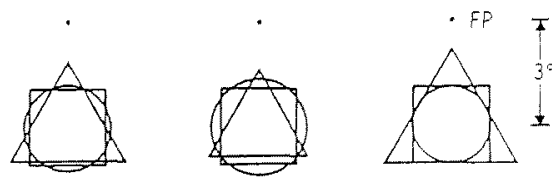

(b)
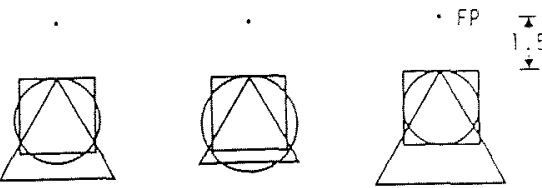

Figure 1. Three geometric figures used in the experiment. The figures are superimposed to indicate spatial relations. Angular separation between the fixation point (FP) and the center of the figure was held constant at $3^{\circ}$ in Experiment $I(a)$, and the separation between FP and the top of the figure was held constant at $1.5^{\circ}$ in Experiment II (b).

\section{Results}

In order to examine the effect of form upon VEPs, subtracted waves (160 summations) were computed by subtracting the waves for control condition from those for figure condition, since there were slight potential changes in the control condition for some subjects.

Figure 2 shows the grand average of the subtracted waves of each figure for three conditions. These are superimposed on the baselines determined by averaging the EEG in the prestimulus period. There were basically identical waveforms in every condition. Judging from the scalp distribution, negative (N1) and positive (P2) waves were clearly identifiable.

Figure 3 shows the grand-averaged peak latencies of $\mathrm{N} 1$ and $\mathrm{P} 2$ at 14 . The mean peak latencies were about $160 \mathrm{~ms}$ and $240 \mathrm{~ms}$, respectively.

Figure 4 shows the grand-averaged amplitude distributions of $\mathrm{N} 1$ and $\mathrm{P} 2$.

A two-way ANOVA (Figure $\times$ Location) was made for the mean peak latency and amplitude of $\mathrm{N} 1$ and $\mathrm{P} 2$ in each stimulus

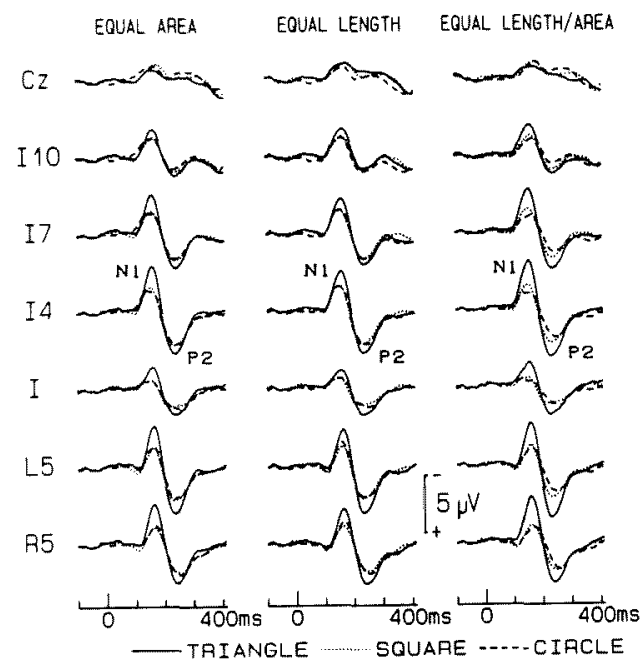

Figure 2. The grand-averaged subtracted waves for the triangle, the square, and the circle in each condition in Experiment $\mathrm{I}$. 
condition. The Tukey test was also given where post-hoc pairwise comparison was required.

On the latency, there were no significant effects of Figure, Location and Figure $x$ Location, the exception being the effects of Location of $\mathrm{N} 1$ and Figure $\times$ Location of $\mathrm{P} 2$ in equal length/area (N1: $F[6,42]=2.75, p<$ $.05 ; \mathrm{P} 2: F[12.84]=2.04, p<.05)$. According to the Tukey test, the $\mathrm{N} 1$ latencies at I and I4 were significantly shorter than those at the other locations $(p s<.01)$.

As to the $\mathrm{Nl}$ amplitude, the main effect of Figure was significant in all stimulus conditions $(F[2,14]=20.09,7.57$ and 27.54 , $p s<$ $.001, .01$ and .001 , respectively). Pairwise comparison showed that the triangle elicited a significantly larger response than did the other figures in each condition (all $p s<.01$ ). No significant difference was observed between the square and the circle. As to the P2 amplitude, the main effect of Figure was significant in equal area and equal length/area $(F[2,14]=4.79$ and 7.9 , ps< .05 and .01 , respectively). Pairwise comparison showed that the triangle evoked significantly larger potentials than did the other figures (both $p s<$ .01). The comparison also showed that the square was of a larger amplitude than the circle in equal length/area $(p<.05)$.

Location effects on the $\mathrm{N} 1$ and $\mathrm{P} 2$ amplitudes were significant in all the conditions

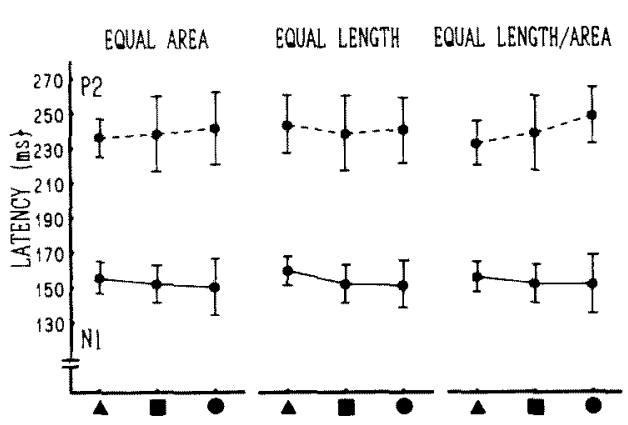

Figure 3. The grand-averaged peak latencies of the $\mathrm{N} 1$ and $\mathrm{P} 2$ waves at Location $\mathrm{I} 4$ in Experiment $\mathrm{I}$. Vertical lines represent standard deviations.
(N1: $F[6,42]=4.21,3.52$ and 4.15 , all $p s<.01$, and $\mathrm{P} 2: F[6,42]=13.97,15.24$ and 13.04 , all $p s<.001$, respectively). A significant effect of Figure $\times$ Location was also obtained in each condition, except for equal area of P2 (N1: $F[12,84]=10.24,2.67$ and 11.29 , $p$ s $<$ $.001, .01$ and .001 , and $\mathrm{P} 2: F[12,84]=5.29$ and 4.02 , both $p s<.001$, respectively). According to Figure 4, the amplitude distributions of $\mathrm{N} 1$ and $\mathrm{P} 2$ show a monopolar change peaking at $\mathbf{I} 4$ in every condition and there seems to be no amplitude difference between the triangle and the other two figures at $\mathrm{Cz}$. The Tukey test confirmed this finding, although the details are not given here.

\section{Experiment II}

In Experiment I geometric figures were presented at $3^{\circ}$ below FP. However, in this spatial arrangement separation between FP and the top of the figure is the smallest for the triangle in all conditions (Figure 1 (a)). Since it has been reported that the VEP sensitivity decreased remarkably within $2^{\circ}$ of fovea (DeVoe, Ripps, \& Vaughan, 1968), we cannot deny the possibility that the difference in separation plays an important role in the present study. This experiment was designed to confirm that similar results are obtained

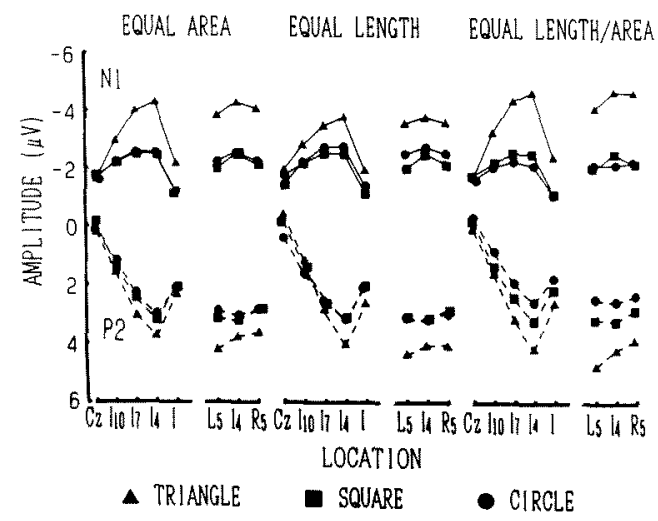

Figure 4 . The grand-averaged amplitude distributions of the N1 and P2 waves in Experiment I. 
when the separation is equalized.

\section{Method}

Subjects. Eight subjects of Experiment I again participated.

Stimulus presentation and VEP recording. Stimulus conditions and procedures were the same as in Experiment I except that the angular separation between FP and the top of the figure was held constant at $1.5^{\circ}$ (Figure 1 (b)).

\section{Results}

Figures 5, 6 and 7 show the results in the same way as in Experiment I. N1 and P2 waves were easily identified.

According to the two-way ANOVA, there were no significant effects of Figure and Figure $\times$ Location for the N1 latency, except for the Location effects in equal area and equal length/area $(F[6,42]=2.55$ and 2.42 , both $p s<.05$ ). The Tukey test showed that the N1 latencies at I and I4 were significantly shorter than those at the other locations ( $p s<$ $.01)$. Regarding the P2 latency, significant effects of the Figure $\times$ Location were shown in equal area and equal length/area $(F[12,84]$ $=2.86$ and $2.04, p s<.01$ and .05 ), but no significant effects of Figure and Location were observed.

As for the amplitude, the main effect of Figure on N1 was significant in every condition $(F[2,14]=17.3,16.82$ and 15.66, all $p s<$ .001 , respectively). Pairwise comparison showed that the triangle elicited significantly larger responses than did the other two figures (all $p s<.01$ ). No significant difference was seen between the square and the circle. Regarding P2, the main effect of Figure was significant in equal length/area $(F[2,14]$ $=6.59, p<.01)$. The Tukey test showed that the triangle evoked a significantly larger response than did the square and the circle $(p s<.01)$.

Concerning the effect of Location, a sig- nificant difference was shown on both NI and $\mathrm{P} 2$ amplitudes in all conditions, except for N 1 of equal length (N1: $F[6,42]=2.46$ and 2.72 , both $p s<.05 ; \mathrm{P} 2: F[6,42]=13.96,14.72$ and 12.79 , all $p s<.001$, respectively). A significant effect of Figure $\times$ Location was also shown in all conditions, except for $\mathrm{P} 2$ of equal length/area $(\mathrm{N} 1: F[12.84]=5.03,3.24$ and 5.58, all $p s<.001, \mathrm{P} 2: F[12,84]=4.09$ and 3.67 , both $p s<.001$, respectively). According to Figure 5, both $\mathrm{N} 1$ and $\mathrm{P} 2$ amplitudes show a monopolar distribution peaking at $\mathrm{I} 4$, as similar to Experiment $\mathrm{I}$. At $\mathrm{Cz}$ there seems to be no difference between the triangle and the other two figures. These findings were confirmed by the Tukey test, but the details are not given here.

\section{Discussion}

Results of the present experiments are summarized as follows: (1)The triangle elicited significantly larger N1 amplitude than did the square and the circle, but no significant difference was found between the square and the circle. (2)The similar effect of form was also shown on the P2 amplitude,

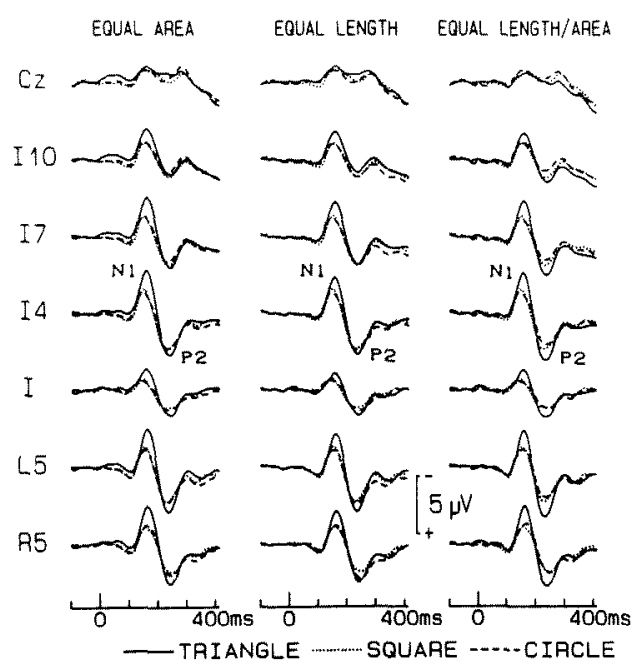

Figure 5. The grand-averaged subtracted waves for three figures in each condition in Experiment II. 
although it was not as distinct as $\mathrm{N} 1$. (3)There was no significant effect of form on the $\mathrm{N} 1$ and $\mathrm{P} 2$ latencies.

As clearly shown, the triangle produced a different effect, especially with the amplitude measure in all stimulus conditions, while the difference between the square and the circle was not clear. These findings confirm our prediction that VEPs show the correspondence to visibility, since the triangle was the most visible in the psychophysical measurements (Torii, 1969; Yokose, 1968; Zusne, 1970).

The results could not be attributed to the smaller angular separation between FP and the top of the figure, since the same effects were obtained where the separation was held constant. Therefore, the finding suggests that the triangle has a stronger impact on the neuronal process around the occipital area, as compared to the square and the circle.

John et al. (1967), using a square, a diamond and a circle, reported that waveforms differed with form more clearly than with area. However, quantitative analysis was not fully made, because they were mainly concerned with specifying the waveforms. Kakigi et al. (1972) conducted an experiment similar to ours, using an equilateral triangle, a square and a circle of equal area on three levels $\left(7,28,112 \mathrm{~cm}^{2}\right)$. Peak-to-peak amplitude for the square was significantly larger

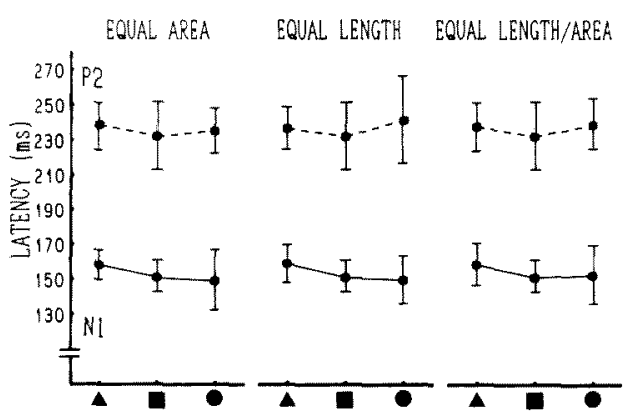

Figure 6. The grand-averaged peak latencies of the $\mathrm{N} 1$ and P2 waves at Location 14 in Experiment II. Vertical lines represent standard deviations. than that for the triangle in $112 \mathrm{~cm}^{2}$. They attributed the result to a smaller retinal size of the square. Although the present result was obtained with the figures of the smaller area, it should be noted that a distinctly different effect of form was shown between the triangle and the other two figures. Moskowitz et al. (1974), using cornered and rounded patterns of equal length, obtained the already mentioned results. Their study is noteworthy in that it successfully disclosed effects of angularity and curvature in the pattern VEPs. However, it is hard to directly compare their data with ours, as their potentials were pattern-reversal.

How could N1 and P2 waves of the present study be compared to those obtained by other studies? In their studies on patternonset VEPs, Jeffreys and Axford (1972a, $1972 b$ ) and Jeffreys (1977) specified three components of $\mathrm{C} 1, \mathrm{C} 2$ and $\mathrm{C} 3 . \mathrm{C} 1$ is assumed to be contrast-specific, while $\mathrm{C} 2$ and C3 are assumed to be contour-specific. Further, Jeffreys (1989) reported that patternonset VEPs consisted of three other types of potentials; the later negative potential (LNP) specific to the relative depth of the stimulus to its background, the later positive potential (LPP) specific to complex and irregular patterns, and face-responsive potentials. C1, C2

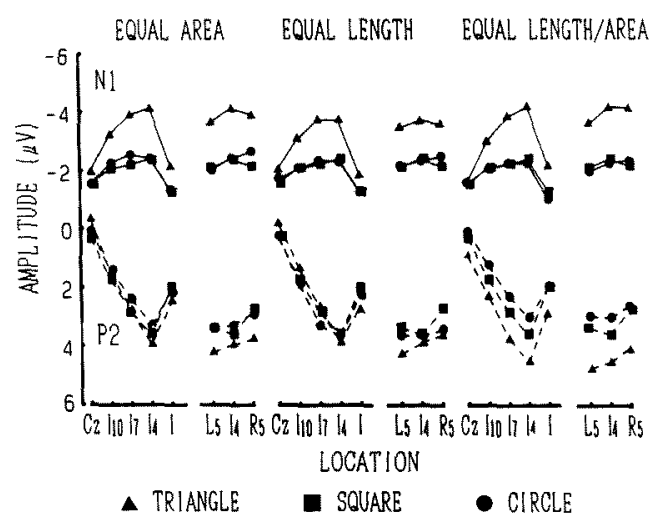

Figure 7. The grand-averaged amplitude distributions of the N1 and P2 waves in Experiment II. 
and $\mathrm{C} 3$ are assumed to derive from the cortical regions with visuotopic organization, while the latter three potentials are from the regions with little or no visuotopic organization. According to our experiments (Ito, Sugata, \& Kuwabara, 1991; Sugata, Ito, Kuwabara, \& Osaka, 1992), Nl seems to consist mainly of $\mathrm{C} 2$, since it showed the polarity reversal based on the visuotopic organization when a figure was presented at the upper part of the visual field. However, it is uncertain whether P2 corresponds to C3, since the definite polarity reversal was not necessarily shown.

Our N1 and P2 latencies were much longer than Jeffreys' (C2: 90-110 ms; C3: $130-150 \mathrm{~ms}$ ). It seems to be attributable to the difference of the experimental conditions between Jeffreys' and our experiments. Regarding the effect of stimulus luminance of the checkerboard upon VEPs, Kriss and Barrett (1985) reviews that reducing the overall stimulus intensity generally results in the increase of latency for all components of onset, offset and reversal responses. Since our luminance was much lower than Jeffreys' $\left(34-540 \mathrm{~cd} / \mathrm{m}^{2}\right)$, this factor in part might have caused the present result. Secondly, we used single outlined figures, while Jeffreys mainly used isolated figures. Consequently, a greater number of figures were presented in a given area and a larger retinal area was stimulated in Jeffreys' condition. This might be the main cause of the present result.

Ermolaev and Kleinman (1983) investigated the effect of background illumination on pattern-onset VEPs, using a dartboard pattern and found that the dominant negativity within the initial $200 \mathrm{~ms}$ consisted of two peaks (N100, which corresponds to $\mathrm{C} 2$ and $\mathrm{N} 130$ ), with $\mathrm{N} 100$ and $\mathrm{N} 130$ being dominant in high and low luminance conditions, respectively. In the present experiments, some subjects showed the N1 waveforms with a notch (the second peak) in some trials.
It seems to be attributable to the condition that our luminance level was low $\left(5 \mathrm{~cd} / \mathrm{m}^{2}\right)$.

Possible relationships of our $\mathrm{N} 1$ and $\mathrm{P} 2$ with the components which Jeffreys and Axford (1972a, 1972b), Jeffreys (1977, 1989) and Ermolaev and Kleinman (1983) mentioned should be examined in further studies.

In the present experiments, spatial orientation of figures was kept constant. However, orientation possibly causes a specific evoked response, since it could be a crucial signal for shape discrimination (Ishii \& Tsuji, 1979). Its effect must therefore be examined in order to specify the form-specific responses.

\section{References}

Barber, C. (Ed.) 1980 Evoked potentials. Lancaster: MTP Press.

Desmedt, J. E. (Ed.) 1977 Visual evoked potentials in man: New developments. Oxford: Clarendon Press.

Desmedt, J. E. (Ed.) 1990 Visual evoked potentials. Amsterdam: Elsevier.

DeVoe, R. G., Ripps, H., \& Vaughan, H. G., Jr. 1968 Cortical responses to stimulation of the human fovea. Vision Research, 8, 135-147.

Dondis, D. A. 1973 A primer of visual literacy. Cambridge, Mass. : The MIT Press.

Ermolaev, R. Y, 1985 Retinal factors affecting visual evoked potentials. In D. Papakostopoulos, S. Butler, \& 1. Martin (Eds.), Clinical and experimental neuropsychophysiology. London: Croom Helm. Pp. 30-65.

Ermolaev, R. Y., \& Kleinman, D. 1983 The effect of background illumination on pattern onset visual evoked potentials. Electroencephalography and clinical Neurophysiology, 55, 546-556.

Ishii, K., \& Tsuji, K. 1979 Discriminatory ability of pattern in the cat: The effect of orientation-free presentation. Japanese Psychological Research, 21, 114-121.

Ito, M. 1986 Influences of the difference of an achromatic color value between the figure and its background upon visual evoked potentials. Bulletin of the Faculty of Letters of Aichi Gakuin University, 16, 1-12. (In Japanese with English summary)

Ito, M. 1987 Influences of the difference of an achro- 
matic color value between the figure and its background upon visual evoked potentials (2). Bulletin of the Faculty of Letters of Aichi Gakuin University, 17, 54-70. (In Japanese with English summary)

Ito, M., Sugata. T., \& Kuwabara, H. 1991 The relationship between figure perception and visual evoked potentials: Effects of figure form (6). The Proceedings of the 55th Amual Convention of the Japanese Psychological Association, 11. (In Japanese)

Ito, M., Sugishita, M., Ito, H., Miyake, S., \& Tsuji, K. 1981 A relationship between the Broca-Sulzer effects and visually evoked potentials. Japanese Psychological Research, 23, 140-148.

Jeffreys, D. A. 1977 The physiological significance of pattern visual evoked potentials. In J. E. Desmedt (Ed.), Visual evoked potentials in man : New developments. Oxford: Clarendon Press. Pp. 134-167.

Jeffreys, D. A. 1989 Evoked potential studies of contour processing in human visual cortex. In J. J Kulikowski, C. M. Dickinson, \& I. J. Murray (Eds.), Seeing contour and colour. London: Pergamon Press. Pp. 529-545.

Jeffreys, D. A., \& Axford, J. G. 1972a Source locations of pattern-specific components of human visual evoked potentials. I. Component of striate cortical origin. Experimental Brain Research, 16. $1-21$.

Jeffreys, D. A., \& Axford, J. G. 1972 b Source locations of pattern specific components of human visual evoked potentials. II. Component of extrastriate cortical origin. Experimental Brain Research, 16, 22-40.

John, E. R., Herrington, R. N., \& Sutton, S. 1967 Effects of visual form on the evoked response. Science, 155, 1439-1442.

Kakigi, S., Miyazaki, M., \& Mori, T. 1972 Effects of stimulus rotation, shape, and visual angle upon human visual evoked response. Japanese Psychological Research, 14, 153-157

Kinney, J. A. S. 1977 Transient visually evoked potential. Journal of the Optical Society of America, 67, 1465-1474.

Kriss, A. \& Barrett, G. 1985 Checkerboard VEPs: A review of stimulus-response relationships. In D. Papakostopoulos, S. Butler, \& I. Martin (Eds.), Clinical and experimental neuropsychophysiolo. gy. London: Croom Helm. Pp. 1-29.

MacKay, D. M., \& Jeffreys, D. A. 1973 Visually evoked potentials and visual perception in man, In R. Jung (Ed.), Handbook of sensory physiolo- gy 7/3B. Berlin: Springer, Pp. 647-648.

Morotomi, T. 1986 Pattern onset, offset and reversal VEPs induced by upper, lower, left and right field stimulátion. Clinical Electroencephalography, 28, 171-181. (In Japanese)

Morotomi, T. 1992 Visual perception and visual evoked potentials: A psychophysiological approach to visual perception. Bulletin of the Faculty of Education, Hokkaido University, 57, 29-116. (In Japanese)

Moskowitz, A. F., Armington, J. C., \& Timberlake, G. 1974 Corners, receptive fields, and visually evoked potentials. Perception and Psychophysics, 15, 325-330.

Nodar, R. H., \& Barber, C. (Eds.) 1984 Evoked potentials II. Stoneham: Butterworth Publishers.

Papakostopoulos, D. Butler, S., \& Martin, I. (Eds.) 1985 Clinical and experimentai neuropsy. chophysiology. London: Croom Helm.

Regan, D. 1977 Steady-state evoked potentials. Journal of the Optical Society of America, 67. 1475-1489

Regan. D. 1989 Human brain electrophysiology: Evoked potentials and evoked magnetic fields in science and medicine. New York: Elsevier.

Regan, D., \& Spekreijse, H, 1986 Evoked potentials in vision research 1951-86. Vision Research, 26, $1461-1480$.

Rietveld. W. J., Tordoir, W. E. M., Hagenouw, J. R. B., Lubbers, J. A., \& Spoor. Th. A. C. 1967 Visual evoked responses to blank and to checkerboard patterned flashes. Acta Physiologica et Pharmacologica Neerlandica, 14, 259-285.

SpehImann, R. 1965 The averaged electrical responses to diffuse and to patterned light in the human. Electroencephalography and clinical Neurophysiology, 19. 560-569.

Sugata, T., Ito, M., Kuwabara, H., \& Osaka, R. 1992 The relationship between figure perception and visual evoked potentials: Effects of figure form (8). The proceedings of the 56th Annual Convention of the Japanese Psychological Association, 849. (In Japanese)

Torii, S. 1969 Form Perception. In Y. Wada, T. Oyama \& S. Imai (Eds.), Handbook of sensory and perceptual psychology. Tokyo: Seishinshobo. Pp. 478-503. (In Japanese)

Yokose, Z. 1968 Psychology of visual perception. 2nd ed. Tokyo: Kyoritsu Shuppan. (In Japanese)

Zusne, L. 1970 Visual perception of form. New York: Academic Press

(Received Dec. 6, 1993; accepted Sept. 3, 1994) 